\title{
Austenite grain growth in alumina-forming austenitic steel - CORRIGENDUM
}

Qiuzhi Gao, Fu Qu, Hailian Zhang, and Qiang Huo

doi: 10.1557/jmr.2016.178, Published by Materials Research Society with Cambridge University Press, 2 May 2016.

In the original publication of "Austenite grain growth in alumina-forming austenitic steel," the legends for the optical micrographs were missing for Fig. 2 and Fig. 3 (a-h). The following are the corrected figures:

\section{REFERENCE}

1. Q. Gao, F. Qu, H. Zhang, and Q. Huo: Austenite grain growth in alumina-forming austenitic steel. J Mater. Res. 31(12), 1732-1740 (2016). doi: 10.1557/jmr.2016.178.

The authors and publisher regret these errors.

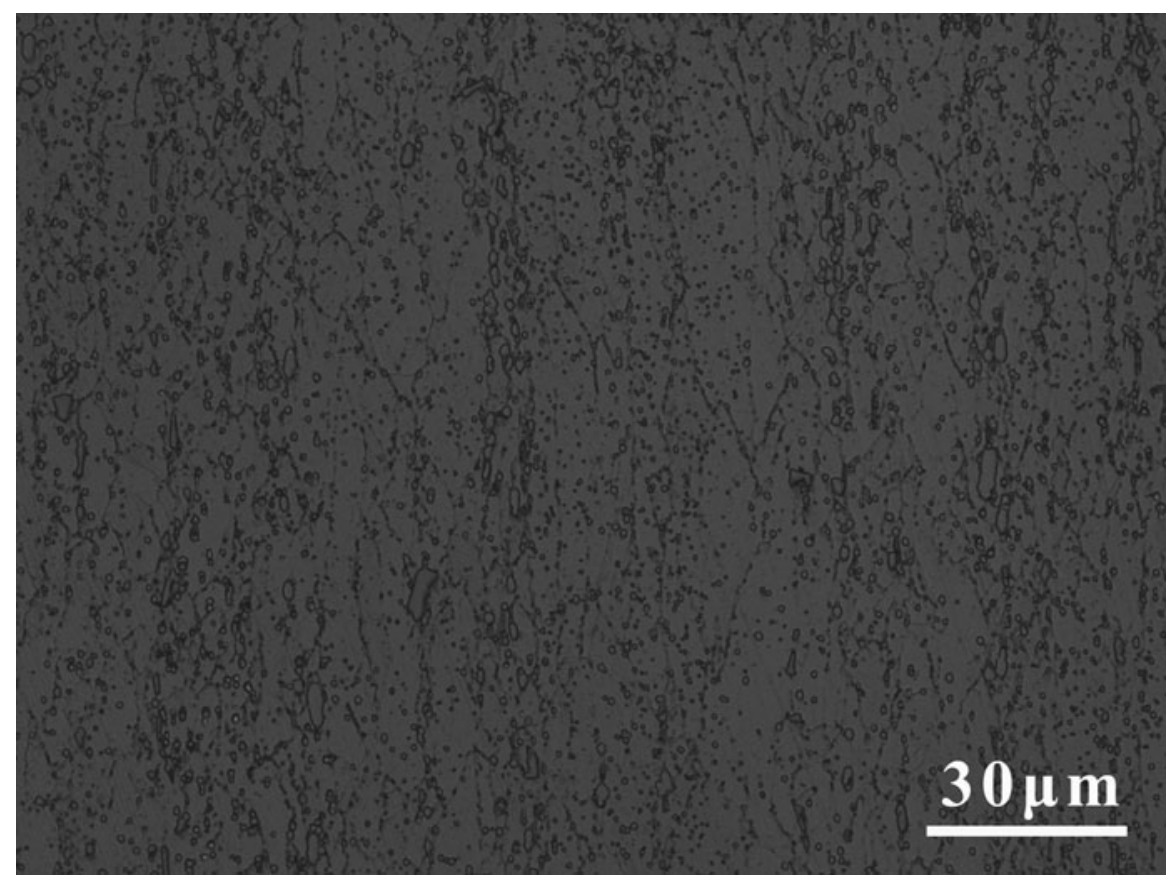

FIG. 2. Optical micrograph of the hot-rolled AFA steel. 


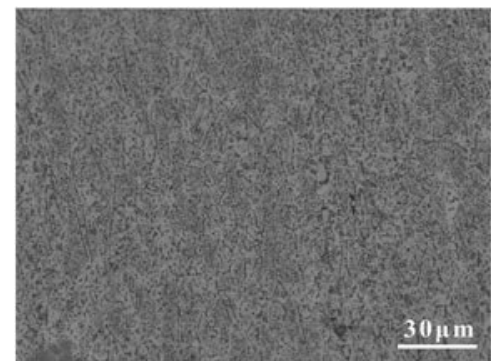

(a)

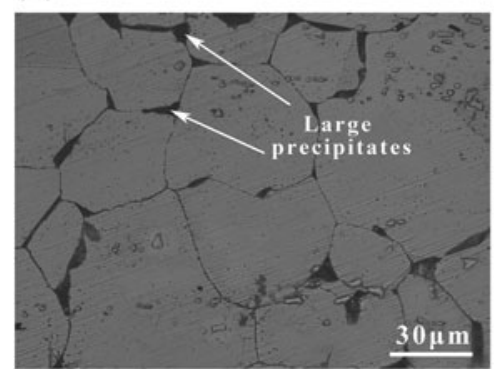

(d)

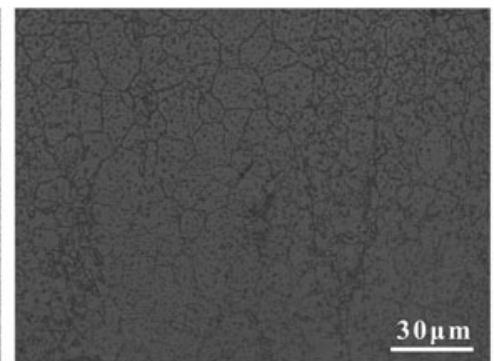

(b)

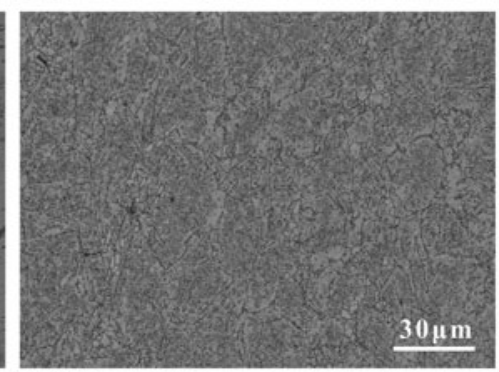

(e)

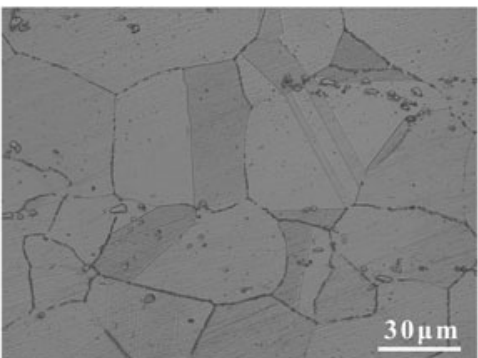

(c)

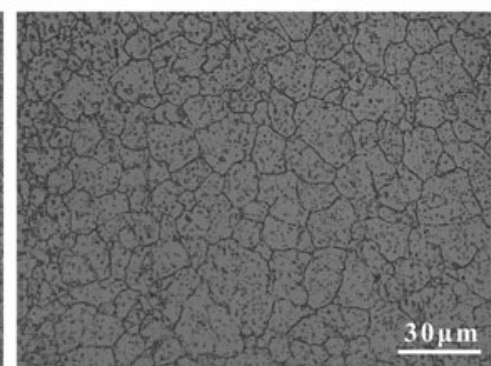

(f)

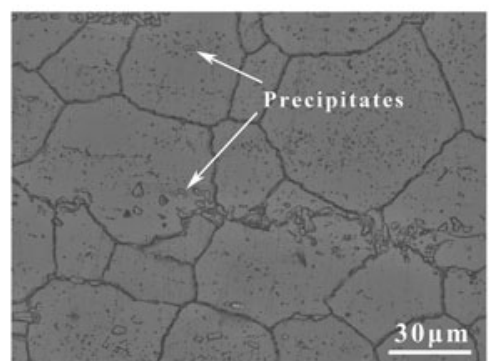

(g)

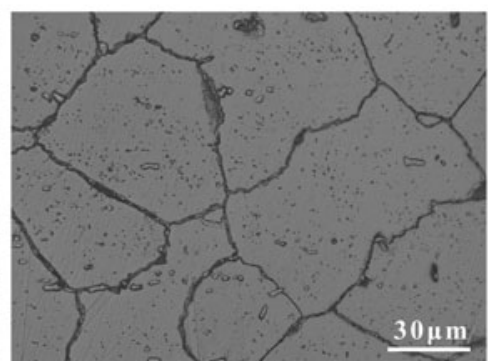

(h)

FIG. 3. Optical micrographs of the AFA steel subjected to normalizing and annealing at various temperatures: normalized at (a) $1273 \mathrm{~K}$, (b) $1373 \mathrm{~K}$, (c) $1473 \mathrm{~K}$, (d) $1523 \mathrm{~K}$, and annealed at (e) $1273 \mathrm{~K}$, (f) $1373 \mathrm{~K}$, (g) $1473 \mathrm{~K}$, (h) $1523 \mathrm{~K}$. 